\title{
Phytosterol-mediated inhibition of intestinal cholesterol absorption is independent of ATP-binding cassette transporter A1
}

\author{
Laura Calpe-Berdiel $^{1,2}$, Joan Carles Escolà-Gil ${ }^{1,2} *$ and Francisco Blanco-Vaca ${ }^{1}$ \\ ${ }^{1}$ Servei de Bioquímica, Hospital de la Santa Creu i Sant Pau, 08025 Barcelona, Spain \\ ${ }^{2}$ Institut de Recerca, Hospital de la Santa Creu i Sant Pau, 08025 Barcelona, Spain \\ (Received 20 July 2005 - Revised 29 September 2005 - Accepted 29 October 2005)
}

\begin{abstract}
An increased activity of ATP-binding cassette transporter (ABC) A1 has been proposed as a mechanism underlying the hypocholesterolaemic effect of phytosterols. In the present study, ABCA1-deficient mice (ABCA1 - - mice) were used to examine the involvement of the ABCA1 in the reduction of intestinal cholesterol absorption in response to a phytosterol-enriched diet. A decrease in intestinal cholesterol absorption of 39 and $35 \%$ was observed after phytosterol treatment in ABCA1 $+/+$ mice and in ABCA1 $-/-$ mice, respectively. No statistically significant changes in plasma lipoprotein profile or in intestinal ABCG5, ABCG8 and Niemann-Pick C1-Like 1 gene expression levels were found when phytosterol-treated ABCA1 -/- mice and untreated ABCA1 - I- mice were compared. We conclude that phytosterol inhibition of cholesterol absorption in mice is independent of ABCA1.
\end{abstract}

Phytosterols: Intestinal cholesterol absorption: ATP-binding cassette transporter A1: Mice

Dietary consumption of phytosterols, or their saturated forms known as stanols, is a recommended therapeutic option to decrease LDL-cholesterol in the most recent guidelines of the National Cholesterol Education Program (Expert Panel on Detection, Evaluation, and Treatment of High Blood Cholesterol in Adults, 2001). Although it has been clearly demonstrated that phytosterols decrease intestinal cholesterol absorption, the mechanisms involved in this action remain unclear (de Jong et al. 2003). One mechanism could be physical competition between phytosterols and cholesterol for incorporation into micelles (de Jong et al. 2003). However, phytosterols do not need to be present in the intestinal lumen simultaneously with cholesterol to inhibit its absorption (Plat et al. 2000). In recent years, important advances in the understanding of intestinal sterol absorption (Sudhop et al. 2005) have provided potential molecular targets of phytosterols. One of these is ATP-binding cassette transporter (ABC) A1 (Brousseau, 2003), especially considering that ABCA1 gene expression increased when Caco-2 cells were incubated with sitostanol added in a micellar solution (Plat \& Mensink, 2002). This transcriptional increase, if maintained at protein level, could decrease ABCA1-mediated intestinal cholesterol absorption (Plat \& Mensink, 2002; Brousseau, 2003). We have used ABCA1-deficient mice to study whether this protein is needed by phytosterols to decrease intestinal cholesterol absorption.

\section{Materials and methods}

Mice and diets

ABCA1 heterozygous mice (ABCA1 +/-) in the DBA/1 background were obtained from Jackson Laboratories (no. 003897;
Bar Harbor, ME, USA) and were crossed to produce wild-type $\mathrm{ABCA} 1+/+$ and ABCA1-deficient (ABCA1 -/-) mice (McNeish et al. 2000). Genotype of the offspring was confirmed by PCR using the wild-type and the targeted allele-specific primers recommended by Jackson Laboratories (http://jaxmice.jax. org/pub-cgi/protocols/protocols.sh). Sex- and age-matched $\mathrm{ABCA} 1+/+$ and $-/-$ were used in our experiments. Eightweek-old $\mathrm{ABCA} 1+/+$ and $-/-$ mice were randomised into two groups and fed either a control Western-type diet (fat, $200 \mathrm{~g} / \mathrm{kg}$; PUFA:saturated fatty acids, 0.07 ; cholesterol, $0.8 \mathrm{~g} / \mathrm{kg}$; protein, $170 \mathrm{~g} / \mathrm{kg}$; fibre, $105 \mathrm{~g} / \mathrm{kg} ;$ Mucedola srl, Settimo Milanese, Milan, Italy) or a $2 \%$ phytosterol-enriched Westerntype diet $(\mathrm{w} / \mathrm{w})$ for 2 weeks. The phytosterol product was composed of $20 \%$ campesterol, $22 \%$ stigmasterol and $41 \%$ $\beta$-sitosterol (Lipofoods S.L., Barcelona, Spain) (Calpe-Berdiel et al. 2005). All the procedures described were approved by the ethical committee of the Ministry of Agriculture, Livestock and Fishing of the Generalitat de Catalunya.

\section{Net intestinal cholesterol absorption}

Net cholesterol absorption was measured in treated and untreated $\mathrm{ABCA} 1+/+$ and $-/-$ mice by a faecal dual-isotope ratio method as previously described (Calpe-Berdiel et al. 2005). Briefly, five mice from each group were intragastrically administered a mixture of $2 \mu \mathrm{Ci}\left[5,6-{ }^{3} \mathrm{H}\right]$ sitostanol (American Radiolabeled Chemicals Inc., St Louis, MO, USA) and $1 \mu \mathrm{Ci}$ $\left[4-{ }^{14} \mathrm{C}\right]$ cholesterol (NEN Life Science Products, Boston, MA, USA). They were then individually housed and stools were collected over the next $3 \mathrm{~d}$. Lipids were extracted from stools with 
isopropyl alcohol-hexane $(2: 3, \mathrm{v} / \mathrm{v})$ and the ${ }^{14} \mathrm{C}:{ }^{3} \mathrm{H}$ ratio in each sample was determined. The percentage of intestinal cholesterol absorption was calculated from these data (Calpe-Berdiel et al. 2005). At the end of the present study, plasma was also taken when mice were killed and ${ }^{14} \mathrm{C}$ counts per min determined.

\section{Plasma and liver lipid analyses}

The methods used for plasma lipid and liver analyses have been described in detail elsewhere (Escola-Gil et al. 2000). Size fractionation of plasma lipoproteins was performed by fast performance liquid chromatography of pooled plasma samples and total cholesterol content on each fraction was then assayed (Escola-Gil et al. 2001).

\section{Quantitative real-time RT PCR analyses}

The small intestine of four animals in each experimental group was removed, flushed with ice-cold saline solution, and cut into three segments with length ratios of 1:3:2 (duodenum-jejunum-ileum). From the middle of each intestinal segment, $1.5 \mathrm{~cm}$ of the duodenal, jejunal, and ileal tissues were cut out and pooled. Small-intestine RNA was isolated using the trizol RNA isolation method (Gibco/BRL, Grand Island, NY, USA). Total RNA samples were repurified, checked for integrity by agarose gel electrophoresis and reverse-transcribed with Oligo(dT) 15 using M-MLV RT, RNase H Minus, Point Mutant to generate cDNA (Calpe-Berdiel et al. 2005). Primer sequences for ABCA1, ABCG5, ABCG8, Niemann-Pick C1-Like 1 protein (NPC1L1) and $\beta$-actin have been published elsewhere (CalpeBerdiel et al. 2005). PCR assays were performed on an Applied Biosystems Prism 7000 sequence detection system (Applied Biosystems, Foster City, CA, USA) as described (Calpe-Berdiel et al. 2005). All analyses were performed in duplicate and relative RNA levels were determined using $\beta$-actin as the internal control.

\section{Statistical analysis}

Results are expressed as mean values and standard deviations. Two-way ANOVA with Bonferroni post hoc tests was performed using GraphPad Prism version 4.0 for Windows (GraphPad Software, San Diego, CA, USA). A value of $P<0.05$ was considered statistically significant.

\section{Results}

Plasma lipid analyses

No differences were found between the lipoprotein pattern of control $\mathrm{ABCA} 1+/+$ mice given phytosterols and those not given phytosterols, which showed that cholesterol was predominantly associated with HDL (Table 1 and Fig. 1(a)). ABCA1 - / - mice exhibited a major increase in non-HDLcholesterol compared with their ABCA1 $+/+$ counterparts concomitant with an HDL-cholesterol deficiency (Table 1). No lipid changes were observed between phytosterol-treated and untreated ABCA1 $-I-$ mice (Table 1) and neither did their lipoprotein pattern differ (Fig. 1(b)).

\section{Net intestinal cholesterol absorption}

$\mathrm{ABCA} 1+/+$ mice given phytosterols presented a $39 \%$ reduction in net intestinal cholesterol absorption compared with non-treated littermates (48.5 (SD 12.3) v. $80 \cdot 0$ (SD 12.1)) (Fig. 2). A similar decrease $(35 \%)$ in net intestinal cholesterol absorption was induced by phytosterol treatment in ABCA1 - /- mice (58.6 (SD 14.6) v. 90.6 (SD 7.3)) (Fig. 2).

The amount of labelled $\left[{ }^{14} \mathrm{C}\right]$ cholesterol in plasma, taken $72 \mathrm{~h}$ after the isotope mixture dosage, was reduced in phytosterol-treated $\mathrm{ABCA} 1+/+$ animals compared with the untreated $\mathrm{ABCA} 1+/+$ group (13 160 (SD 476) v. 22480 (SD 5807) counts per min; $P<0.05)$ and also in phytosterol-treated ABCA1 - / - compared with untreated ABCA1 $-/-$ mice (19 240 (SD 7266) v. 50880 (SD 8394) counts per min; $P<0.05$ ).

\section{Real-time RT PCR analyses}

The relative intestine mRNA levels of ABCA1, ABCG5, ABCG8 and NPC1L1 were determined (Fig. 3). Two-way ANOVA of RT-PCR analysis revealed a significant effect of genotype on intestinal ABCA1 expression (Fig. 3). However, untreated control $(\mathrm{ABCA} 1+/+)$ and $\mathrm{ABCA} 1-/-$ mice showed no differences in the gene expression of transporters ABCG5, ABCG8 and NPC1L1 compared with those consuming plant sterols (Fig. 3).

\section{Discussion}

Transcriptional activation of ABCA1 has been proposed as a mechanism to explain the decrease in intestinal net cholesterol absorption induced by phytosterols (Plat \& Mensink, 2002).

Table 1. Effects of phytosterols on plasma lipoproteins and liver cholesterol content in ATP-binding cassette transporter (ABC) $A 1+/+$ and $A B C A 1-/-$ mice after 2 weeks on each diet (eight animals per group)

(Mean values and standard deviations)

\begin{tabular}{|c|c|c|c|c|c|c|c|c|c|}
\hline & \multicolumn{4}{|c|}{$\mathrm{ABCA} 1+/+$ mice } & \multicolumn{4}{|c|}{$\mathrm{ABCA} 1-/-$ mice } & \multirow{3}{*}{$\begin{array}{l}\text { Effect of } \\
\text { genotype }(P)\end{array}$} \\
\hline & \multicolumn{2}{|c|}{ Control } & \multicolumn{2}{|c|}{$2 \%$ Phytosterols } & \multicolumn{2}{|c|}{ Control } & \multicolumn{2}{|c|}{$2 \%$ Phytosterols } & \\
\hline & Mean & SD & Mean & SD & Mean & SD & Mean & SD & \\
\hline Plasma total cholesterol (mм) & 3.5 & 1.5 & 3.3 & 0.9 & $2 \cdot 0$ & 1.6 & 1.9 & 0.6 & $<0.01$ \\
\hline Plasma non-HDL-cholesterol (mM) & 0.9 & 0.6 & 0.9 & 0.3 & 1.9 & $1 \cdot 2$ & $1 \cdot 7$ & $1 \cdot 0$ & $<0.05$ \\
\hline Liver cholesterol ( $\mu \mathrm{mol} / \mathrm{g}$ tissue) & 0.8 & 0.6 & 0.6 & 0.2 & 0.8 & 0.2 & $1 \cdot 1$ & $0 \cdot 1$ & NS \\
\hline
\end{tabular}

*Two-way ANOVA. 

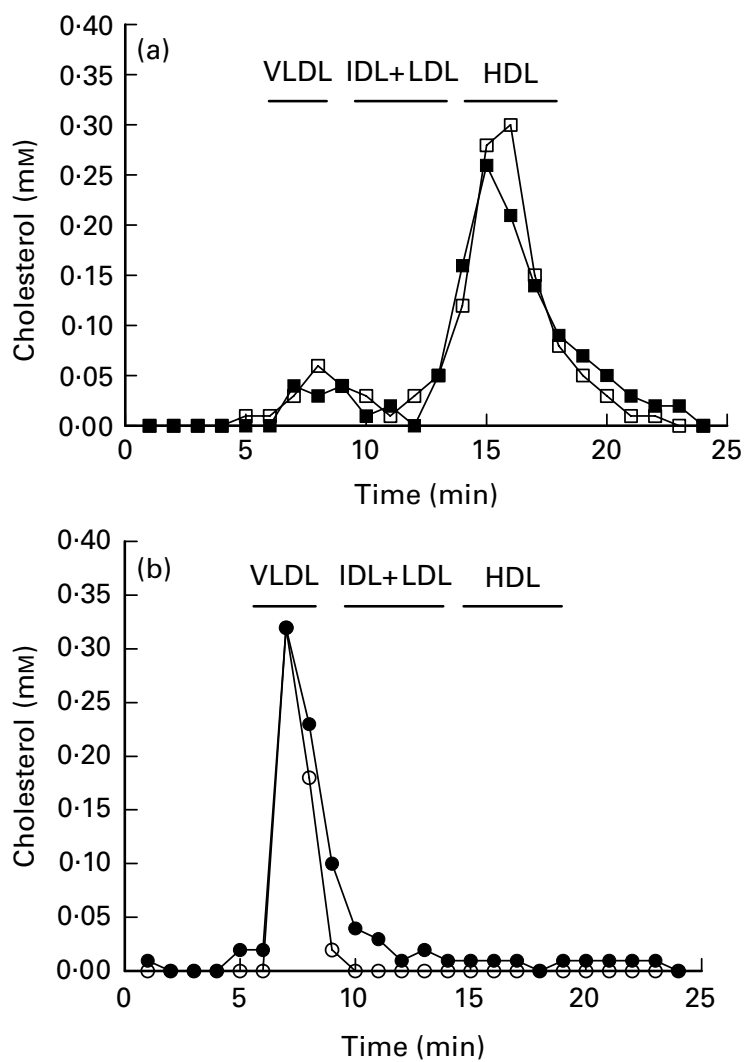

Fig. 1. Plasma lipoprotein cholesterol distribution determined by fast performance liquid chromatography in (a) ATP-binding cassette transporter (ABC) $\mathrm{A} 1+/+$ and (b) ABCA1 - I- mice, both fed a Western-type diet with or without phytosterols. Pooled mouse plasma $(200 \mu \mathrm{l})$ from the different genotypes was analysed. The positions of elution of the VLDL, intermediate-density lipoproteins (IDL) + LDL and HDL are represented by horizontal lines. (- $\square-$ ), $\mathrm{ABCA} 1+/+$ mice fed control diet; $(-\mathbf{-}-), \mathrm{ABCA} 1+/+$ mice fed diet with $2 \%$ phytosterols; $\left(-\mathrm{O}_{-}\right)$, ABCA1 $-/-$mice fed control diet; (-๑-), ABCA1 $-/-$ mice fed diet with $2 \%$ phytosterols.

Furthermore, phytosterols or their derivatives could act as liver $\mathrm{X}$ receptor ligands and increase ABCA1 expression at a transcriptional level (Kaneko et al. 2003; Plat et al. 2005). However, the importance of ABCA1 in net intestinal cholesterol absorption is unclear (Brousseau, 2003). Several reports in animal models, although not all (Groen et al. 2001), have provided substantial in vivo evidence that ABCA1 influences intestinal net cholesterol absorption (McNeish et al. 2000; Drobnik et al. 2001; Mulligan et al. 2003; Temel et al. 2005). However, ABCA1 is dominantly expressed on the basolateral surface of intestinal cells (Ohama et al. 2002) and liver X receptor activation increases intestinal cholesterol excretion independently of $\mathrm{ABCA} 1$, probably by increasing the intestinal transcription of ABCG5 and ABCG8 (Plosch et al. 2002). ABCG5/G8 heterodimers may exchange phytosterols and cholesterol in the intestinal lumen (Plosch et al. 2002; Sehayek, 2003). NPC1L1 is a critical mediator of cholesterol absorption as revealed in mice lacking a functional NPC1L1 (Altmann et al. 2004). Thus, activation of these $\mathrm{ABC}$ transporters and the reduction in NPC1L1 could also explain the phytosterol-mediated inhibition of intestinal net cholesterol absorption (Duan et al. 2004; Davies et al. 2005).

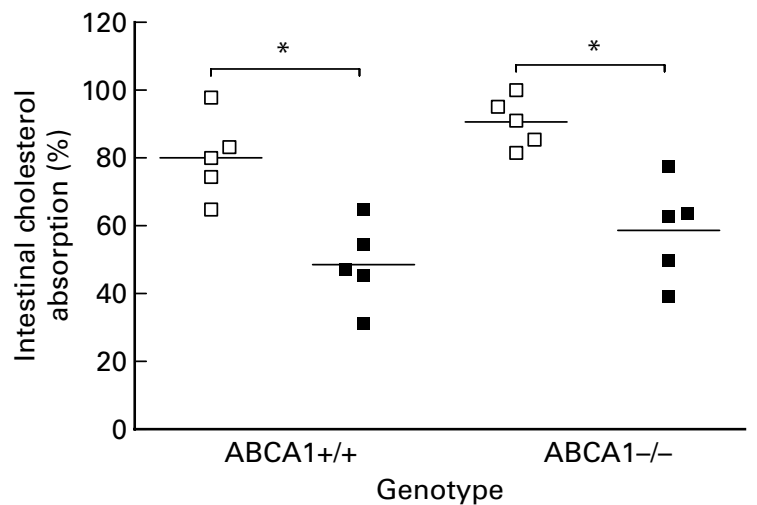

Fig. 2. Effects of phytosterols on intestinal net cholesterol absorption in ATPbinding cassette transporter $(\mathrm{ABC}) \mathrm{A} 1+/+$ and $\mathrm{ABCA} 1-/-$ mice. The group means from five animals in each group are indicated by horizontal bars. ( $\square$ ), Control diet; $(\square)$, diet with $2 \%$ phytosterols. * Two-way ANOVA and Bonferroni post hoc tests revealed significant effects of phytosterols $(P<0.01)$.

We have reported that dietary plant stanols and sterols decrease intestinal net cholesterol absorption regardless of increases or decreases in intestinal gene expression of ABCA1, ABCG5/G8 and in NPC1L1 in apoE $-/-$ mice, LDL receptor-deficient mice and C57BL/6 mice (Calpe-Berdiel et al. 2005). Other authors have reported similar results in hamsters (Field et al. 2004). An oxidised plant sterol metabolite has also been found to enhance intestinal $\mathrm{ABC}$ expression in $\mathrm{C} 57 \mathrm{BL} / 6$ mice (Kaneko et al. 2003). Liver X receptor activation with increased ABCA1 gene expression has also been described in Caco-2 cells after the addition of plant sterols and stanols from the 4-desmethylsterol family (Plat et al. 2005). However, in our opinion, there is no conclusive explanation for the differences observed between the different models and thus it cannot be ruled out that phytosterols changed the activity of these transporters through post-transcriptional mechanisms. Furthermore, these results do not permit differentiation between primary and compensatory changes (Kaneko et al. 2003; Field et al. 2004; Calpe-Berdiel et al. 2005; Plat et al. 2005).

In the present study, we analysed the involvement of ABCA1 as a molecular target of phytosterols. The major finding was that ABCA1 do not play an essential role in the phytosterolmediated reduction in net cholesterol absorption since the effect of phytosterols was similar in ABCA $1-/-$ and ABCA1 $+/+$ mice. Of note, we found very low, but not undetectable, intestinal mRNA ABCA1 in ABCA1 - /- mice. This has also been found by other groups (Plosch et al. 2002; Timmins et al. 2005) and may be due to the fact that the PCR primers were located outside the disrupted exons (McNeish et al. 2000).

We did find a modest increase in net cholesterol absorption in untreated ABCA1 $-/-$ mice with regard to untreated $\mathrm{ABCA} 1+/+$ animals. Although the cause of this increase is unknown, this observation is consistent with previous observations made during the characterisation of these animals (McNeish et al. 2000) but in contrast to that of another group that studied intestinal net cholesterol absorption in ABCA1 - /- mice fed a cholesterol-free diet (Drobnik et al. 2001). We found no major compensatory changes in the intestinal gene expression of other sterol transporters such as ABCG5, ABCG8 or NPC1L1. 

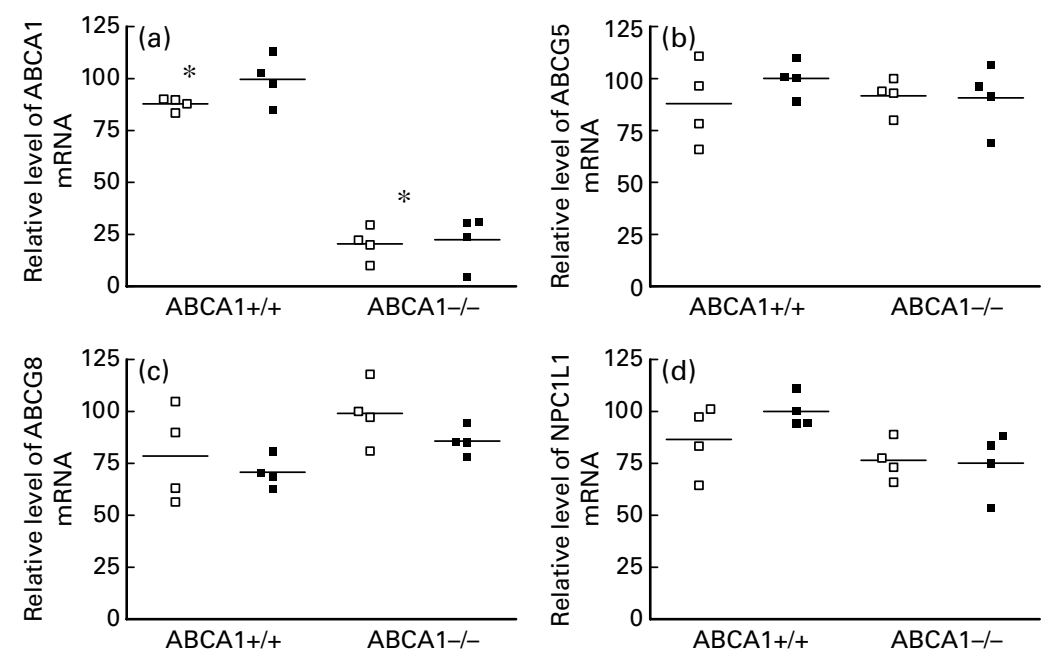

Fig. 3. Relative intestinal ATP-binding cassette transporter (ABC) A1 (a), ABCG5 (b), ABCG8 (c) and Niemann-Pick C1-Like 1 (NPC1L1) (d) mRNA levels in $\mathrm{ABCA} 1+1+$ and $\mathrm{ABCA} 1-1-$ mice after 2 weeks fed a Western-type diet with or without phytosterols. The most abundant signal was set to a normalised value of 100 arbitrary units. The group means from four animals in each group are indicated by horizontal bars. Putatively inactive mRNA was detectable in ABCA1 - /- mice, as the PCR primers were located outside the disrupted exons. ( $\square$ ), Control diet; ( $\square$ ), diet with $2 \%$ phytosterols. * Two-way ANOVA and Bonferroni post hoc tests revealed a significant effect of genotype $(P<0.01)$.

The decreased plasma labelled $\left[{ }^{14} \mathrm{C}\right]$ cholesterol at $72 \mathrm{~h}$ in phytosterol-fed ABCA1 $+/+$ mice compared with non-treated $\mathrm{ABCA} 1+/+$ mice may be due to the decreased intestinal net cholesterol absorption in the first group. In contrast, the increased plasma radioactivity in ABCA $1-/-$ mice compared with $\mathrm{ABCA} 1+/+$ could be due only in part to their increased intestinal net cholesterol absorption. The increase in VLDL particles observed in ABCA1 - / - animals fed a Western-type diet has also been described previously (McNeish et al. 2000). Thus, elevated radioactivity in ABCA1 - /- mice may also be due to enhanced VLDL particle formation (Plosch et al. 2002; Sahoo et al. 2004) and/or reduced catabolism of apoB-containing lipoproteins (Joyce et al. 2003). In fact, the increase (2-fold) in plasma cholesterol radioactivity and non-HDL-cholesterol found in $\mathrm{ABCA} 1-/-$ mice, compared with $\mathrm{ABCA} 1+/+$ mice, is consistent.

Interestingly, phytosterol treatment did not decrease plasma cholesterol in either of the two mouse genotypes, although a reduction in intestinal net cholesterol absorption was observed in both models. We and other authors have reported that wildtype mice and gerbils fed a low-cholesterol diet present unchanged low plasma cholesterol concentrations regardless of manipulations that alter intestinal net cholesterol absorption, such as treatment with ezetimibe or phytosterols (Repa et al. 2002; Calpe-Berdiel et al. 2005; Hayes et al. 2005). Thus, it is possible that with a non-expanded whole-body pool of cholesterol, as occurs in mice with low non-HDL-cholesterol, changes in cholesterol synthesis compensate for the decrease in net intestinal absorption. However, detailed studies will be required to prove this hypothesis. In preliminary experiments we found no change in either liver cholesterol (Table 1) or HMGCoA reductase gene expression (data not shown).

In conclusion, the present results clearly demonstrate that ABCA1 is not the primary transporter involved in the reduction in intestinal net cholesterol absorption induced by phytosterols in mice. The wide availability in the future of other GM mice, such as ABCG5-, ABCG8- and NPC1L1-deficient mice, should permit an in vivo evaluation of other potential targets of phytosterols.

\section{Acknowledgements}

We are grateful to Glòria Rodríguez Pedregosa for helpful advice in the genotyping of animals, Christine O'Hara for editorial assistance and Lipofoods S.L. (Gavà, Barcelona) for phytosterol preparation. The study was supported by grants FIS C03-08, 051921 and G03-181. J. C. E.-G. is a Ramón y Cajal researcher of the Ministerio de Educación y Ciencia.

\section{References}

Altmann SW, Davis HR Jr, Zhu LJ, et al. (2004) Niemann-Pick C1 Like 1 protein is critical for intestinal cholesterol absorption. Science $\mathbf{3 0 3}$, 1201-1204.

Brousseau M (2003) ATP-binding cassette transporter A1, fatty acids, and cholesterol absorption. Curr Opin Lipidol 14, 35-40.

Calpe-Berdiel L, Escola-Gil JC, Ribas V, Navarro-Sastre A, Garces-Garces J \& Blanco-Vaca F (2005) Changes in intestinal and liver global gene expression in response to a phytosterol-enriched diet. Atherosclerosis 181, 75-85.

Davies JP, Scott C, Oishi K, Liapis A \& Ioannou YA (2005) Inactivation of NPC1L1 causes multiple lipid transport defects and protects against diet-induced hypercholesterolemia. $J$ Biol Chem 280, $12710-12720$.

de Jong A, Plat J \& Mensink RP (2003) Metabolic effects of plant sterols and stanols (review). J Nutr Biochem 14, 362-369.

Drobnik W, Lindenthal B, Lieser B, et al. (2001) ATP-binding cassette transporter A1 (ABCA1) affects total body sterol metabolism. Gastroenterology 120, 1203-1211.

Duan LP, Wang HH \& Wang DQ (2004) Cholesterol absorption is mainly regulated by the jejunal and ileal ATP-binding cassette sterol efflux transporters ABCG5 and ABCG8 in mice. J Lipid Res 45, $1312-1323$.

Escola-Gil JC, Julve J, Marzal-Casacuberta A, Ordonez-Llanos J, Gonzalez-Sastre F \& Blanco-Vaca F (2000) Expression of human apolipoprotein A-II in apolipoprotein E-deficient mice induces features of familial combined hyperlipidemia. J Lipid Res 41, 1328-1338.

Escola-Gil JC, Julve J, Marzal-Casacuberta A, Ordonez-Llanos J, Gonzalez-Sastre F \& Blanco-Vaca F (2001) ApoA-II expression in 
CETP transgenic mice increases VLDL production and impairs VLDL clearance. J Lipid Res 42, 241-248.

Expert Panel on Detection, Evaluation, and Treatment of High Blood Cholesterol in Adults (2001) Executive Summary of The Third Report of The National Cholesterol Education Program (NCEP) Expert Panel on Detection, Evaluation, And Treatment of High Blood Cholesterol in Adults (Adult Treatment Panel III). JAMA 285, 2486-2497.

Field FJ, Born E \& Mathur SN (2004) Stanol esters decrease plasma cholesterol independently of intestinal $\mathrm{ABC}$ sterol transporters and Niemann-Pick C1-Like 1 protein gene expression. J Lipid Res 45, 2252-2259.

Groen AK, Bloks VW, Bandsma RH, Ottenhoff R, Chimini G \& Kuipers F (2001) Hepatobiliary cholesterol transport is not impaired in ABCA1null mice lacking HDL. $J$ Clin Invest 108, 843-850.

Hayes KC, Pronczuk A, Wijendran V \& Beer M (2005) Free phytosterols facilitate excretion of endogenous cholesterol in gerbils. J Nutr Biochem 16, 305-311.

Joyce C, Freeman L, Brewer HB Jr \& Santamarina-Fojo S (2003) Study of ABCA1 function in transgenic mice. Arterioscler Thromb Vasc Biol 23, 965-971.

Kaneko E, Matsuda M, Yamada Y, Tachibana Y, Shimomura I \& Makishima M (2003) Induction of intestinal ATP-binding cassette transporters by a phytosterol-derived liver X receptor agonist. J Biol Chem 278, 36091-36098.

McNeish J, Aiello RJ, Guyot D, et al. (2000) High density lipoprotein deficiency and foam cell accumulation in mice with targeted disruption of ATP-binding cassette transporter-1. Proc Natl Acad Sci USA 97, $4245-4250$.

Mulligan JD, Flowers MT, Tebon A, Bitgood JJ, Wellington C, Hayden MR \& Attie AD (2003) ABCA1 is essential for efficient basolateral cholesterol efflux during the absorption of dietary cholesterol in chickens. J Biol Chem 278, 13356-13366.

Ohama T, Hirano K, Zhang Z, et al. (2002) Dominant expression of ATPbinding cassette transporter-1 on basolateral surface of Caco-2 cells stimulated by LXR/RXR ligands. Biochem Biophys Res Commun 296, 625-630.
Plat J \& Mensink RP (2002) Increased intestinal ABCA1 expression contributes to the decrease in cholesterol absorption after plant stanol consumption. FASEB J 16, 1248-1253.

Plat J, Nichols JA \& Mensink RP (2005) Plant sterols and stanols: effects on mixed micellar composition and LXR (target gene) activation. $J$ Lipid Res 46, 2468-2476.

Plat J, van Onselen EN, van Heugten MM \& Mensink RP (2000) Effects on serum lipids, lipoproteins and fat soluble antioxidant concentrations of consumption frequency of margarines and shortenings enriched with plant stanol esters. Eur J Clin Nutr 54, 671-677.

Plosch T, Kok T, Bloks VW, Smit MJ, Havinga R, Chimini G, Groen AK \& Kuipers F (2002) Increased hepatobiliary and fecal cholesterol excretion upon activation of the liver $\mathrm{X}$ receptor is independent of ABCA1. J Biol Chem 277, 33870-33877.

Repa JJ, Dietschy JM \& Turley SD (2002) Inhibition of cholesterol absorption by $\mathrm{SCH} 58053$ in the mouse is not mediated via changes in the expression of mRNA for ABCA1, ABCG5, or ABCG8 in the enterocyte. J Lipid Res 43, 1864-1874.

Sahoo D, Trischuk TC, Chan T, Drover VA, Ho S, Chimini G, Agellon LB, Agnihotri R, Francis GA \& Lehner R (2004) ABCA1-dependent lipid efflux to apolipoprotein A-I mediates HDL particle formation and decreases VLDL secretion from murine hepatocytes. J Lipid Res 45, $1122-1131$.

Sehayek E (2003) Genetic regulation of cholesterol absorption and plasma plant sterol levels: commonalities and differences. J Lipid Res 44, 2030-2038.

Sudhop T, Lutjohann D \& von Bergmann K (2005) Sterol transporters: targets of natural sterols and new lipid lowering drugs. Pharmacol Ther 105, 333-341.

Temel RE, Lee RG, Kelley KL, Davis MA, Shah R, Sawyer JK, Wilson MD \& Rudel LL (2005) Intestinal cholesterol absorption is substantially reduced in mice deficient in both ATP-binding cassette transporter A1 (ABCA1) and acyl-CoA:cholesterol O-acyltransferase 2 (ACAT2). J Lipid Res 46, 2423-2431.

Timmins JM, Lee JY, Boudyguina E, et al. (2005) Targeted inactivation of hepatic ABCA1 causes profound hypoalphalipoproteinemia and kidney hypercatabolism of apoA-I. J Clin Invest 115, 1333-1342. 